\title{
Can Graft vs. Leukemia Effect Be Uncoupled From Graft vs. Host Disease? An Examination of Proportions
}

\author{
Elizabeth Krieger ${ }^{1}$ and Amir Ahmed Toor ${ }^{2 *}$ \\ ${ }^{1}$ Department of Pediatrics, Virginia Commonwealth University, Richmond, VA, United States, ${ }^{2}$ Department of Internal \\ Medicine, Massey Cancer Center, Virginia Commonwealth University, Richmond, VA, United States
}

Keywords: hematopoietic cell transplantation, graft vs. host disease, graft vs. leukemia effect, whole exome sequencing, tumor vaccination

\section{OPEN ACCESS}

Edited by:

Marieke Griffioen

Leiden University Medical

Center, Netherlands

Reviewed by:

Paul Armistead,

University of North Carolina at Chape

Hill, United States

Benjamin Garrett Vincent,

University of North Carolina at Chapel Hill, United States

${ }^{*}$ Correspondence:

Amir Ahmed Toor

amir.toor@vcuhealth.org

Specialty section:

This article was submitted to

Cancer Immunity and Immunotherapy,

a section of the journal

Frontiers in Immunology

Received: 15 December 2019

Accepted: 06 April 2020

Published: 28 April 2020

Citation:

Krieger $E$ and Toor AA (2020) Can

Graft vs. Leukemia Effect Be

Uncoupled From Graft vs. Host

Disease? An Examination of

Proportions. Front. Immunol. 11:777.

doi: 10.3389/fimmu.2020.00777
Hematopoietic cell transplantation (HCT) provides potentially curative therapy for high-risk hematological malignancies, predominantly through alloreactivity mediated by donor immune effectors directed at a recipient's malignant cells; this is termed graft vs. leukemia (GVL) effect (1). This beneficial effect has historically been associated with a similar donor immune attack on normal recipient tissues, graft vs. host disease (GVHD) (2). At this time both of these entities, GVL and GVHD are considered to be stochastically determined, i.e., prior to transplant one cannot reliably determine which patient will develop one or both outcomes. The high complexity of the system at hand which includes patients with different malignancies, varying human leukocyte antigen (HLA) types, and different immune effectors involved in these processes has meant that logic-based therapeutic choices which impact variables associated with GVL are studied by determining the probability of the desired clinical outcomes in large populations of patients. Such studies have allowed an incremental improvement in the clinical outcomes of recipients of similarly HLA matched donor HCT. The introduction of high-resolution HLA matching and HLA DPB1 matching were both such incremental changes which helped improve survival in recipients from HLA matched HSC donors (3-5). Despite these advances, the apparent randomness in the potential for developing alloreactivity remains. This apparent randomness derives, in part from these phenomena having their origin at a molecular level, with the recognition of minor histocompatibility antigens (mHA) and tumor specific antigens (TSA) bound to HLA molecules on the antigen presenting cells (APC), by unique T cell receptors (TCR) on T cell clones. This recognition triggers $\mathrm{T}$ cell responses which effect the observed clinical outcomes.

To develop a deeper understanding of the alloreactive processes governing the relative balance of GVHD and GVL one has to understand the antigenic landscape at hand in a HCT recipient at the molecular level. Herein is presented a model which examines the relative difference in the genetic potential for developing either GVL, using tumor specific antigen (TSA) burden, or likelihood of developing GVHD, using minor histocompatibility antigens (mHA). Historically haematopoietically restricted mHA (6-8), cancer testis antigens (9), protein splice variants (10) and in some instances even retroviral elements (11) have been implicated in producing GVL effects, with some of these elements also contributing to GVHD. While haematopoietically restricted mHA have been implicated in the development of GVHD and protection from relapse (12), HLA presentation is a prerequisite for this to occur (13). Thus, far $\sim 60$ haematopoietically restricted minor histocompatibility antigens have been described with antigen presentation restricted to a limited spectrum of HLA allotypes, precluding broad utility in patients (7). Thus, to optimize clinical outcomes, it is imperative to develop 
methodology which will allow personalized computation of the probability of GVHD or GVL developing in unique HCT donorrecipient pairs.

Hematological malignancies are driven by DNA mutations which develop in normal cells over time as a result of exposure to external mutagens and intrinsic processes, such as errors in DNA replication (14). The mutational burden of adult cancers ranges widely; for example, solid tumors may average from 33 to 66 somatic mutations which alter their protein structure and function. Cancers such as, melanoma and lung cancer are on an extreme end of this spectrum, possessing $\sim 200$ mutations per tumor, and thus are susceptible to immune therapy (15). On the opposite end of this spectrum, hematologic malignancies have some of the lowest mutational burdens, with leukemias harboring $\sim 9.6$ mutations per tumor (14, 16-20). Mutated genes expressed in these tumors may be recognized as nonself-proteins by the immune system, and targeted by the GVL mechanism (21).

Point mutations were first shown to induce a naturally occurring $\mathrm{T}$ cell response in a patient with melanoma (22). However, initial studies of cancer immunotherapy were hampered by technological challenges encountered in deriving patient specific TSA libraries. In the past decade, next generation sequencing (NGS) or "deep" sequencing has allowed the sequencing of thousands of small fragments of DNA in parallel, such that an entire genome may be rapidly sequenced (23). NGS has allowed cataloging of the entire library of potential TSA in a variety of human malignancies. The full impact of this knowledge of individualized genetic profiling of cancers was first observed when utilizing programed death receptor PD-1 and programed death-ligand (PDL) receptor inhibitors. Check point blockade allows unimpeded autologous TSA specific T cell mediated killing, which is most significant in tumors with a higher mutational burden, as there are theoretically more TSA presented on $\mathrm{MCH}$ class I and class II molecules with a greater mutational burden $(14,24,25)$.

In contrast, the relatively low mutational burden of hematologic malignancies does not meet the thereshold necessary to effectively utilize immunotherapy and PD1/PDL1 blockade $(26,27)$. Common hematologic driver mutations including NPM1 which are expressed in $30-35 \%$ of cases of AML have been shown to be expressed by AML blasts and may be targeted by TCR gene transfer (28). Several other specific mutations including BCR-ABL, WT1, and PR1 have also been shown to effect outcomes after HCT (29-31). Nevertheless, such unique mutations are usually not adequate to generate an intrinsic GVL response in the vast majority of patients. Despite this relative dearth of tumor associated neo-antigens, hematological malignancies have proven to be susceptible to the GVL effect of an allograft, some times without GVHD developing (32-34). One may therefore ask, is it possible to apply NGS to the transplant setting in order to understand how one may uncouple GVL from GVHD in the majority of patients? This goal has been sought by many a group who have tried to better predict GVHD and GVL by examining biomarkers (35), cytokines $(36,37)$, mass spectrometry data $(38)$, natural killer cell markers (39). Modification of the conditioning and GVHD prophylaxis regimens have also been attempted to accomplish the dissociation of GVHD from GVL (40-43). However, while all of these factors play important roles in the GVHD and GVL phenomenon, if both at their core are centered on peptide presentation and immune attack, it is not likely that we can always dissociate GVL from GVHD.

A computational approach may be taken to develop a partial understanding of the GVHD-GVL balance in HLA matched HCT. As stated above, on average hematologic malignancies contain $\sim 10$ protein coding, exomic mutations which may be immunogenic. For patients with these and other TSA resulting from mutations, logically in each individual, the number of tumor specific peptide antigens presented will then depend on their HLA type, the specific mutations and the spectrum of mutated peptides presented by those HLA molecules. As an example, a study of over 600 patients with multiple myeloma showed an average of 64 nonsynonymous mutations. Neoantigen load was then predicted in silico by identifying mutant peptides predicted to bind class I HLA molecules. Predicted neoantigen were defined as any unique peptide: HLA combination with mutant binding affinity IC50 less then $500 \mathrm{nM}$. This revealed the average predicted neoantigens to be 23 in number, with 9 expressed neoantigens. This outlines the fact that not all neoantigens are either expressed or presented on HLA (17). This number then gives an approximate estimate of the isolated GVL inducing potential for multiple myeloma. However, the average number of nonsynonymous mutations in leukemia is typically much lower, as noted above. If we were to extrapolate using the ratio of 64 nonsynonymous mutations to its 9 expressed neoantigens, one could predict that hypothetically hematologic malignancy on average would be unlikely to express $>10$ neoantigens. In actual fact the true number of TSA will vary with each individual based on the number of nonsynonymous mutations present, type of mutation (i.e., point vs. frame shift mutations) their antigenicity, cleavage potential of the proteins harboring the mutations, the HLA binding affinities of the mutant peptides and the HLA type in an individual, among other factors. While, this may underestimate of the expressed neoantigens burden of hematologic malignancy, a study of antigen presentation of multiple malignancy types including hematologic malignancies and solid tumors indicated that there are $\sim 1.5$ expressed neoantigens per point mutation and 4 per frameshift mutation (44), suggesting that the estimate presented here is not too far from reality.

This may hold true even if one considers other TSA sources that may contribute to GVL, including those derived from normally repressed proteins such as cancer testis antigens. These are antigens normal expressed in "immunologically privileged sites" such as, testicular or trophoblastic tissues, and are thus immunogenic. When expressed, these will offer a potential GVL target, which will not be dependent on TSA, and will add to the TSA burden. However, there is variability introduced at the response end of this cascade, since some of these mutations may lead to too strong a TCR affinity and down regulation by central tolerance, while others with a more optimal affinity being allowed to escape central tolerance while still allowing allowreactivity 


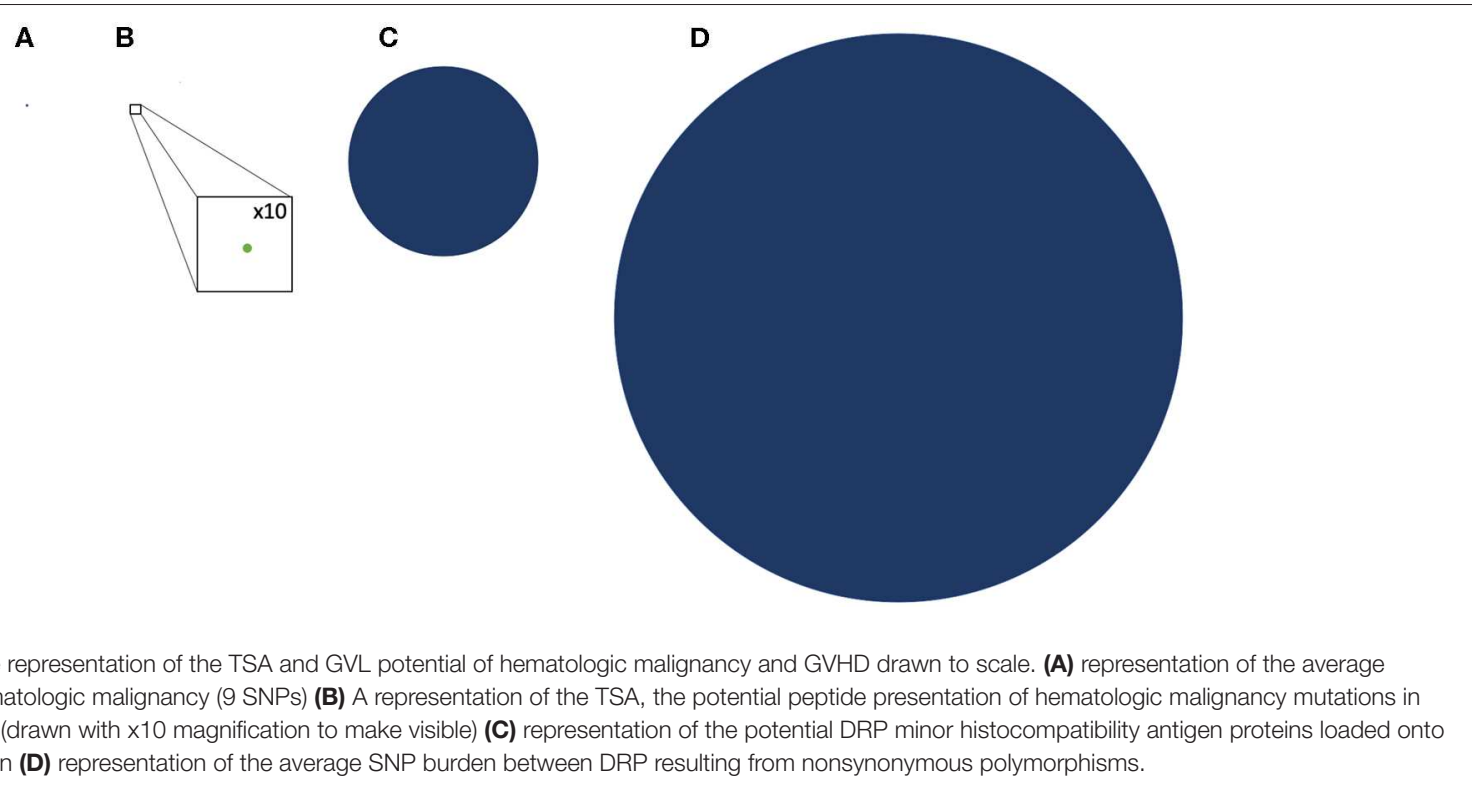

(45). All in all, it is unlikely that most hematological malignancies have a very large abundance of TSA to drive an isolated GVL phenomenon.

With an estimate of the TSA in hematological malignancies established, one may next attempt to determine how likely it is to unravel GVL from GVHD. NGS also offers a perspective into the genetic background of GVHD alloreactivity. Exome sequencing in both hematopoietic stem cell as well as solid organ transplant recipients has demonstrated a vast library of potential mHA which provide an alternative set of targets for donor T cells. Whole exome sequencing (WES) of transplant donors and recipients was performed in a group of HLA matched donors and recipients, and demonstrated an average of $>6,000$ non-synonymous single nucleotide polymorphisms (SNP) per HLA matched donor-recipient pair (DRP) (46). These polymorphisms when translated into peptide sequences in silico, yielded an average of 2,254 peptides/DRP with the potential to bind HLA-A, -B and -C molecules with intermediate to high affinity (IC50 of $<50 \mathrm{nM}$, NetMHCpan ver2.0) (47) and represented an alloreactivity potential for a given HSCT DRP. The SNPs when compared to the mutations used to estimate TSA, are much larger in number, indicating that mHA may provide the dominant antigen background in terms of generating alloreactivity following HCT. Similar data regarding the extent of genomic variation between transplant donors and recipients have been reported by other groups investigating genomic variation in transplant recipients, in both solid organ transplants (48) and in HCT (49-53), as well as in models predicting GVL specific libraries (54). This abundance of SNPs across the exome in unique HCT donor-recipient pairs is an eye-opening finding compared to the average 10 mutations per hematologic neoplasm. This relative antigen abundance of potential mHA compared to the potential TSA estimate is graphically depicted to scale in Figure 1.
While the sheer number of mHA alone vastly outnumbers the potential TSA in hematologic malignancy, these numbers do not tell the whole story. Whether the potential mHA result in a $\mathrm{T}$ cell proliferation depends on several factors, such as peptide cleavage potential, antigen binding affinity, and critically, $\mathrm{T}$ cell clones bearing receptors that might recognize the mHA-HLA complexes. Crucially, the T cell receptor affinity for HLA-mHA or HLA-TSA complexes also needs to be adequate to ensure T cell engagement and activation. Mathematical modeling of T cell expansion in response to these HLA-antigen complexes has given important insights into the quantitative principles at hand in these processes. First, the expansion of donor T cells recognizing specific antigens will be proportional to the amount of antigen available, i.e., the expression level of the antigen bearing protein will determine the extent of $\mathrm{T}$ cell expansion. Secondly, this $\mathrm{T}$ cell expansion is likely governed by the affinity of the antigen to the HLA molecule, and the affinity of the T cell receptors for antigen-HLA complex. This is an exponential relationship, with $\mathrm{T}$ cell growth increasing non-linearly in response to changing affinity. An important clue to this is provided by the $\mathrm{T}$ cell clonal frequency distribution which follows Power Law when these are plotted out for $\mathrm{T}$ cell clones present in normal individuals (55).

\section{$T$ cell frequency $\propto$ Antigen expression $\times e^{m H A-H L A}$ affinity $\times$ TCR affinity}

Based on the above model, an alloreactive donor cytotoxic $\mathrm{T}$ cell response was simulated. To do this the array of $\mathrm{mHA}$ in each patient was considered as an operator matrix modifying a hypothetical cytotoxic $\mathrm{T}$ cell clonal vector matrix. Utilizing the basic assumption that $\mathrm{T}$ cell expansion will be governed by the binding affinity of the variant peptide to HLA, and for model estimation of antigen driven $\mathrm{T}$ cell proliferation, assuming unit affinity of the TCR for each mHA-HLA complex (since this was not known for this particular set of antigens), each responding $\mathrm{T}$ 


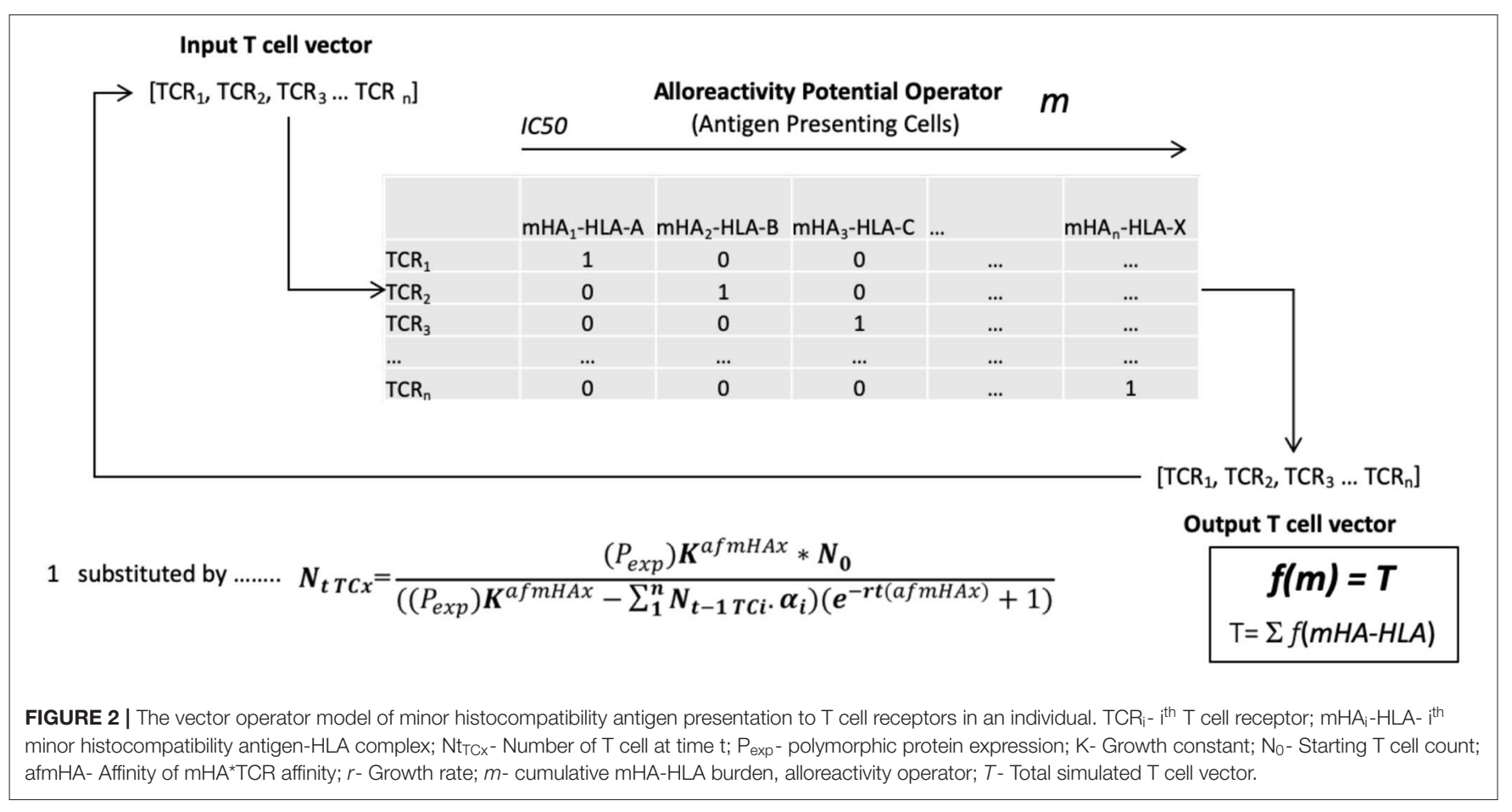

cell clone's proliferation was determined by the logistic equation of growth (Figure 2). Assuming uniform growth conditions, $r$ values in the logistic equation, these simulations, showed that the simulated organ-specific alloreactive $\mathrm{T}$ cell clonal growth had marked variability, with orders of magnitude of difference between different HLA matched DRPs $(N=78)$. This was because of the differences in the unique polymorphic peptide sequences and their binding to the many different HLA types. In this study higher total and organ-specific $\mathrm{T}$ cell counts were associated with the incidence of moderate to severe GVHD (56). $\mathrm{T}$ cell growth in these simulations exhibited a sigmoid, logistic dynamic over time similar to immune reconstitution kinetics exhibited by allograft recipients (57). This model predicted the emergence of a limited number of dominant $\mathrm{T}$ cell clones responding to highly expressed and high affinity mHA-HLA class I complexes unique to each individual depending on their HLA type. On the other hand, there was a large number of low frequency clones responding to poorly expressed protein-derived mHA, weakly bound to the corresponding HLA. When the model was adjusted to incorporate competition with dominant higher affinity clones, it demonstrated chaotic dynamics with suppression of the lower affinity clones in early time points, identifying this as a possible contributor to the stochasticity observed in the clinical setting. Further, once variability in TCR affinity for the mHA-HLA complexes is accounted for in this model, then the even greater variability and randomness in $\mathrm{T}$ cell responses may be observed between different donorrecipient pairs. Change in the term for growth rate, $r$ in the model will have profound impact on the variability seen and GVHD risk. When evaluated for HLA class II molecule presentation, these alloreactive mHA libraries further expanded several-fold given the longer peptide sequences which may bind HLA class II molecules, increasing the mathematical complexity at hand. Nevertheless, this work demonstrates that these antigen arrays are susceptible to mathematical modeling and thus of potential use in estimating the likelihood of GVHD occurring in HLA matched (or mismatched) SCT DRP (58). Such estimates will potentially serve to personalize GVHD prophylaxis regimens to allow optimal GVL effect in future trials, while suppressing GVHD.

With these data in mind, when the relative number of tumor specific antigens and minor histocompatibility antigens are examined it becomes obvious that the relatively small number of TSA compared with $\mathrm{mHA}$, may in most individuals result in outcompeting of tumor specific targets, by normal tissue targets setting up the field for GVL occurring in the company of GVHD (Figure 1). Thus, polymorphic normal recipient antigens (mHA) expressed in the malignant clones will be more likely to be presented to the donor $\mathrm{T}$ cells and contribute to a relapse-free-state, than TSA. The mathematics are further complicated by the possibility that the TSA compete not only with the mHA for presentation, but also with the nonpolymorphic/non-antigenic peptides in the recipient's tissues, which will far outnumber both these sets of peptides, since these will also be loaded onto the HLA molecules and presented to the donor helper and cytotoxic $\mathrm{T}$ cells. The mathematics dealing with this problem were introduced in the paper by Salman et al. It is also imperative that the immunogenic antigens have peptides with an affinity to both HLA class I and HLA class II molecules and be expressed in a particular malignancy in an individual for those to be effective at provoking an immune response. 

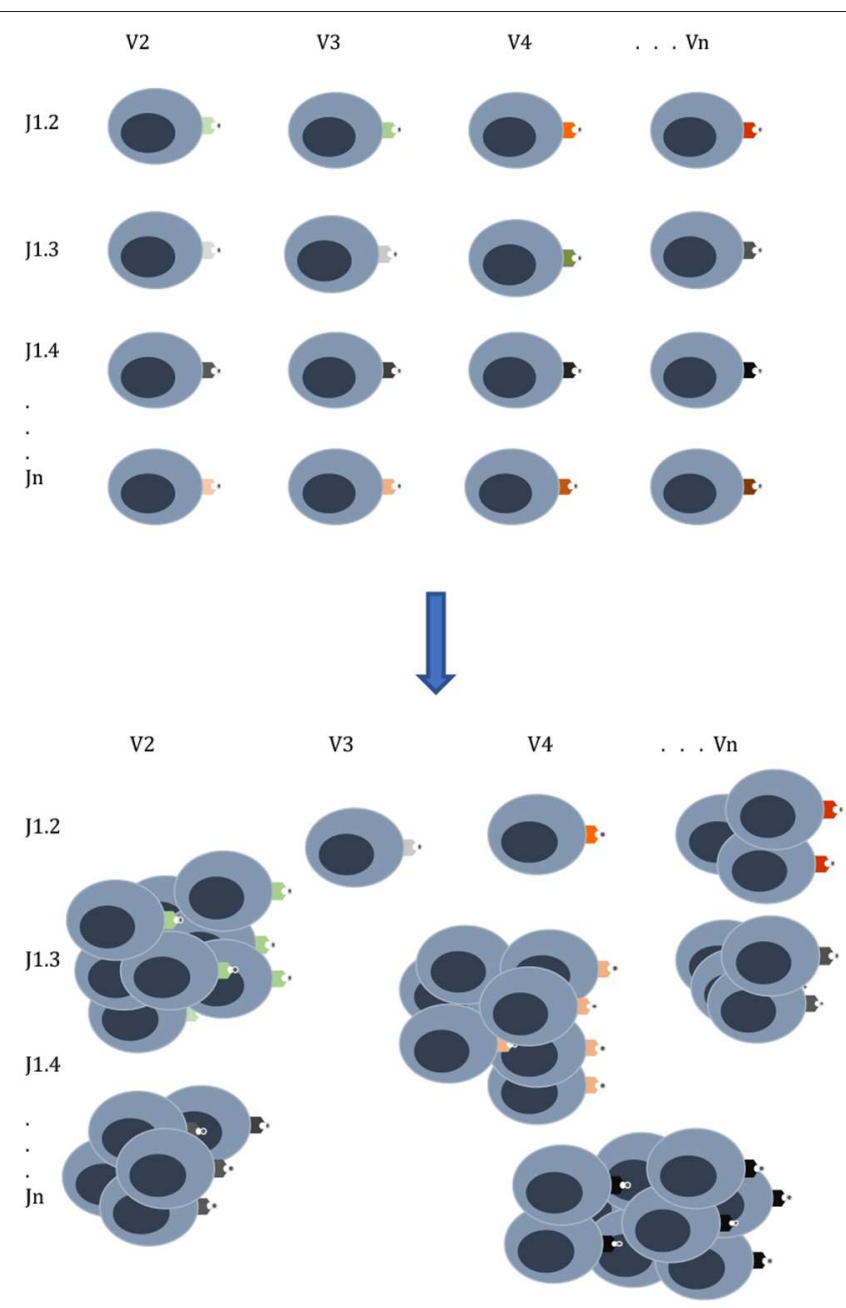

$\underline{O R}$

$\mathrm{J} 1.2$

V2

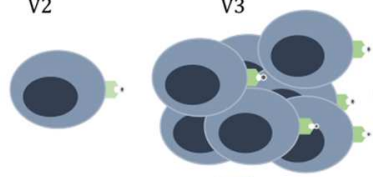

J1.3

J1.4

in

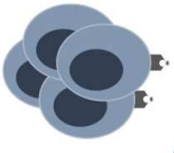

V4
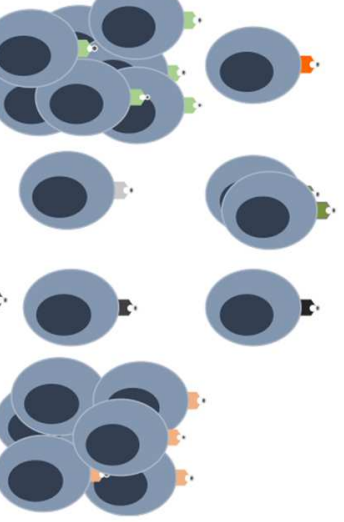

FIGURE 3 | T cell clonal proliferation will depend on affinity and abundance of antigen at the time of initial exponential expansion. The donor graft has a T cell clonal repertoire with the potential to react to many different antigens. Once infused into the recipient the $T$ cell clones expand in proportion to the relative antigen affinity and abundance as can be seen in two different scenarios emerging from the same donor cell infusion. Other factors which will influence this growth are cytokines, degree of tissue injury and pharmacotherapy for GVHD prophylaxis. 
All is not lost in the mathematical medley of chaos and combinatorics. It is clear that the quantitatively driven $\mathrm{T}$ cell responses depend on relative antigen abundance and HLA affinity. Traditionally HSCT is done with patients in remission, and as immunosuppression is withdrawn, they may develop chronic GVHD, which confers protection from relapse, and in a few patients GRFS might be observed. This likely depends on both the extent of $\mathrm{T}$ cell clonal diversity emerging after transplantation, as well as the balance of antigen expression. It is therefore critical to understand the notion of relative antigen abundance (Figure 3), such that to elicit an effective immune response an antigen has to be present in an adequate quantity. Such relative antigen abundance of TSA and mHA may be modulated by vaccination using TSA, as has been reported in melanoma patients (59). This may increase the likelihood of GVL developing in a GVHD-free state in patients with hematological malignancies. It is important to recognize the logistic growth kinetics of $\mathrm{T}$ cell clones with an early exponential growth phase, and the importance of timing in vaccine administration before the onset of this growth. Another approach already in practice is to use hypomethylating agents to alter the expression of immunogenic cancer testis antigens (9). This therapy provides an extensive library of alternative immune targets for the donor $\mathrm{T}$ cells to focus on and has been successfully combined with donor lymphocyte infusions to treat post allograft relapse (60). It is to be recognized that this model only partially encompasses the complexity of normal and post-transplant immune responses and does not give a complete explanation for the GVHD-GVL dissociation observed in patients who experience GRFS, That state represents a complex interplay of the factors described here with conditioning regimens and GVHD prophylaxis, and of course tumor growth kinetics. Antigen presentation triggered by tissue injury and cytokine release are critical factors in these calculations, as are

\section{REFERENCES}

1. Bleakley M, Riddell SR, Cancer FH. Molecules and mechanisums of the graft-versus-lleukemia. Nat Rev. (2004) 4:1-10. doi: 10.1038/nrc1365

2. Horowitz MM, Gale RP, Sondel PM, Goldman JM, Kersey J, Kolb HJ, et al. Graft-versus-leukemia reactions after bone marrow transplantation. Blood. 75:555-62.

3. Lee SJ, Klein J, Haagenson M, Baxter-Lowe LA, Confer DL, Eapen M., et al. High-resolution donor-recipient HLA matching contributes to the success of unrelated donor marrow transplantation. Blood. (2007) 110:457683. doi: 10.1182/blood-2007-06-097386

4. Harvey J, Green A, Cornish J, Steward C, Cummins M, Keen L., et al. Improved survival in matched unrelated donor transplant for childhood ALL since the introduction of high-resolution matching at HLA class $i$ and II. Bone Marrow Transplant. (2012) 47:1294-300. doi: 10.1038/bmt.2012.8

5. Fleischhauer K, Shaw BE, Gooley T, Malkki M, Bardy P, Bignon JD., et al. Effect of T-cell-epitope matching at HLA-DPB1 in recipients of unrelateddonor haemopoietic-cell transplantation: a retrospective study. Lancet Oncol. (2012) 13:366-74. doi: 10.1016/S1470-2045(12)70004-9

6. Goulmy E, De Bueger M, Bakker AJJ, Rood V, Van Der Woude F. Tissue Distribution of Human Minor. (1992). Available online at: http://www. jimmunol.org/content/149/5/1788 (accessed February 14, 2020).

7. Spierings E. Minor histocompatibility antigens: past, present, and future. Tissue Antigens. (2014) 84:374-60. doi: 10.1111/tan.12445 pharmacological suppression of $\mathrm{T}$ cell growth, and elimination of T cell clones.

In conclusion, mathematical modeling of immune reconstitution, guided by NGS, along with an in-depth analysis of the relative expansion of donor $\mathrm{T}$ cell clones in response to the differentially expressed TSA and normal recipient antigens in individual patients, may allow a deeper understanding of the apparently stochastic nature of clinical outcomes observed at a population level. Mathematical modeling of $\mathrm{T}$ cell responses has revealed the chaotic dynamics of posttransplant immune responses, when multiple antigens with different HLA binding affinities and tissue expression levels are studied $(58,61,62)$. Thus, stochasticity is built into the system, however, the probability windows for GVHD-GVL determination, may be narrowed by a using tools such as NGS of normal and malignant recipient, as well as donor exomes, and mathematical simulation of alloreactive $\mathrm{T}$ cell responses to mHA and TSA. These strategies can be used to identify the optimal TSA which would yield a T cell response, and these may then be used to derive tumor specific vaccines, altering the relative antigen abundance at crucial early times following SCT. Thus, in-depth genomic analysis may eventually allow us to truly develop precision medicine tools for optimizing patient outcomes following SCT.

\section{AUTHOR CONTRIBUTIONS}

EK and AT developed the idea and wrote the manuscript.

\section{FUNDING}

AT was supported by research funding from the NIH-NCI Cancer Center Support Grant (P30-CA016059; PI: Gordon Ginder, MD).
8. Mutis T. Targeting alloreactive donor T-cells to hematopoietic systemrestricted minor histocompatibility antigens to dissect graft-versusleukemia effects from graft-versus-host disease after allogeneic stem cell transplantation. Int J Hematol. (2003) 78:208-12. doi: 10.1007/BF02983796

9. Toor AA, Payne KK, Chung HM, Sabo RT, Hazlett AF, Kmieciak M., et al. Epigenetic induction of adaptive immune response in multiple myeloma: sequential azacitidine and lenalidomide generate cancer testis antigen-specific cellular immunity. Br J Haematol. (2012) 158:700-11. doi: 10.1111/j.1365-2141.2012.09225.x

10. Ren X, Deng R, Zhang K, Sun Y, Teng X, Li J. SpliceRCA:in situ single cell analysis of mRNA splicing variants. ACS Cent Sci. (2018) 4:6807. doi: 10.1021/acscentsci.8b00081

11. Chiappinelli KB, Strissel PL, Desrichard A, Li H, Henke C, Akman B., et al. Inhibiting DNA methylation causes an interferon response in cancer via dsRNA including endogenous retroviruses. Cell. (2015) 162:97486. doi: 10.1016/j.cell.2015.07.011

12. Spierings E, Kim YH, Hendriks M, Borst E, Sergeant R, Canossi A., et al. Multicenter analyses demonstrate significant clinical effects of minor histocompatibility antigens on GvHD and GvL after HLA-matched related and unrelated hematopoietic stem cell transplantation. Biol Blood Marrow Transplant. (2013) 19:1244-53. doi: 10.1016/j.bbmt.2013.06.001

13. Larsen ME, Kornblit B, Larsen MV, Masmas TN, Nielsen M, Thiim M., et al. Degree of predicted minor histocompatibility antigen mismatch correlates with poorer clinical outcomes in nonmyeloablative allogeneic 
hematopoietic cell transplantation. Biol Blood Marrow Transplant. (2010) 16:1370-81. doi: 10.1016/j.bbmt.2010.03.022

14. Grove CS, Vassiliou GS. Acute myeloid leukaemia: a paradigm for the clonal evolution of cancer? DMM Dis Model Mech. (2014) 7:94151. doi: $10.1242 / \mathrm{dmm} .015974$

15. Goodman AM, Kato S, Bazhenova L, Patel SP, Frampton GM, Miller V., et al. Tumor mutational burden as an independent predictor of response to immunotherapy in diverse cancers. Mol Cancer Ther. (2017) 16:2598608. doi: 10.1158/1535-7163.MCT-17-0386

16. Vogelstein B, Papadopoulos N, Velculescu VE, Zhou S, Diaz LA, Kinzler KW. Cancer genome landscapes. Science. (2013) 340:1546-58. doi: 10.1126/science.1235122

17. Miller A, Asmann Y, Cattaneo L, Braggio E, Keats J, Auclair D., et al. High somatic mutation and neoantigen burden are correlated with decreased progression-free survival in multiple myeloma. Blood Cancer J. (2017) 7:e612. doi: 10.1038/bcj.2017.94

18. Lawrence MS, Stojanov P, Polak P, Kryukov GV, Cibulskis K, Sivachenko A., et al. Mutational heterogeneity in cancer and the search for new cancerassociated genes. Nature. (2013) 499:214-8. doi: 10.1038/nature12213

19. Alexandrov LB, Nik-Zainal S, Wedge DC, Aparicio SA, Behjati S, Biankin $\mathrm{AV}$., et al. Signatures of mutational processes in human cancer. Nature. (2013) 500:415-21. doi: 10.1038/nature12477

20. Zehir A, Benayed R, Shah RH, Middha S, Kim HR, Srinivasan $\mathrm{P}$, et al. Mutational landscape of metastatic cancer revealed from prospective clinical sequencing of 10,000 patients. Nat Med. (2017) 23:703-13. doi: 10.1038/nm.4333

21. Gubin MM, Artyomov MN, Mardis ER, Schreiber RD. Tumor_neoantigens_building_a_.PDF. J Clin Invest. (2015) 125:3413-21. doi: 10.1172/JCI80008

22. Lennerz V, Fatho M, Gentilini C, Frye RA, Lifke A, Ferel D., et al. The response of autologous $\mathrm{T}$ cells to a human melanoma is dominated by mutated neoantigens. Proc Natl Acad Sci USA. (2005) 102:160138. doi: 10.1073/pnas.0500090102

23. Behjati S, Tarpey PS. What is next generation sequencing? Arch Dis Child Educ Pract Ed. (2013) 98:236-8. doi: 10.1136/archdischild-2013-304340

24. Johnson DB, Frampton GM, Rioth MJ, Yusko E, Xu Y, Guo X., et al. Targeted next generation sequencing identifies markers of response to PD-1 blockade. Cancer Immunol Res. (2016) 4, 959-67. doi: 10.1158/2326-6066.CIR-16-0143

25. Campesato LF, Barroso-Sousa R, Jimenez L, Correa BR, Sabbaga J, Hoff PM., et al. Comprehensive cancer-gene panels can be used to estimate mutational load and predict clinical benefit to PD-1 blockade in clinical practice. Oncotarget. (2015) 6:34221-7. doi: 10.18632/oncotarget.5950

26. Jelinek T, Mihalyova J, Kascak M, Duras J, Hajek R. PD-1/PD-L1 inhibitors in haematological malignancies: update 2017. Immunology. (2017) 152:35771. doi: $10.1111 / \mathrm{imm} .12788$

27. Pianko MJ, Goldberg AD, Lesokhin AM. Clinical development of PD-1 blockade in hematologic malignancies. Cancer. 24:315. doi: 10.1097/ppo.0000000000000297

28. van der Lee DI, Reijmers RM, Honders MW, Hagedoorn RS, de Jong RC, Kester MG., et al. Mutated nucleophosmin 1 as immunotherapy target in acute myeloid leukemia. J Clin Invest. (2019) 129:774-85. doi: 10.1172/JCI97482

29. Molldrem JJ, Lee PP, Wang C, Felio K, Kantarjian HM, Champlin RE., et al. Evidence that specific T lymphocytes may participate in the elimination of chronic myelogenous leukemia. Nat Med. (2000) 6:101823. doi: $10.1038 / 79526$

30. Karas M, Steinerova K, Lysak D, Hrabetova M, Jungova A, Sramek J., et al. Pre-transplant quantitative determination of NPM1 mutation significantly predicts outcome of ailogeneic hematopoietic stem cell transplantation in patients with normal karyotype AML in complete remission. Anticancer Res. (2016) 36:5487-98. doi: 10.21873/anticanres.11130

31. Stringaris K, Marin D, Barrett AJ, Hills R, Sobieski C, Cao K., et al. KIR gene haplotype: An independent predictor of clinical outcome in MDS patients. Blood. (2016) 128:2819-23. doi: 10.1182/blood-2016-05-713099

32. Park SS, Jeon YW, Min GJ, Park S, Yahng SA, Yoon JH., et al. Graft-versus-host disease-free, relapse-free survival after allogeneic stem cell transplantation for myelodysplastic syndrome. Biol Blood Marrow Transplant. (2019) 25:6372. doi: 10.1016/j.bbmt.2018.08.004
33. Nazha A, Rybicki L, Abounader D, Bolwell B, Dean R, Gerds AT., et al. GvHDfree, relapse-free survival after reduced-intensity allogeneic hematopoietic cell transplantation in older patients with myeloid malignancies. Bone Marrow Transplant. (2016) 51:1642-43. doi: 10.1038/bmt.2016.254

34. Solomon SR, Sizemore C, Zhang X, Ridgeway M, Solh M, Morris LE., et al. Current graft-versus-host disease-free, relapse-free survival: a dynamic endpoint to better define efficacy after allogenic transplant. Biol Blood Marrow Transplant. (2017) 23:1208-14. doi: 10.1016/j.bbmt.2017.02.022

35. Chen YB, Cutler CS. Biomarkers for acute GVHD: Can we predict the unpredictable. Bone Marrow Transplant. (2013) 48:755-60. doi: 10.1038/bmt.2012.143

36. Grimm J, Zeller W, Zander AR. Soluble interleukin-2 receptor serum levels after allogeneic bone marrow transplantation as a marker for GVHD. Bone Marrow Transplant. (1998) 21:29-32. doi: 10.1038/sj.bmt.1701041

37. Levine JE. Implications of TNF- $\alpha$ in the pathogenesis and management of GVHD. Int J Hematol. (2011) 93:571-7. doi: 10.1007/s12185-011-0803-1

38. Kaiser T, Kamal H, Rank A, Kolb HJ, Holler E, Ganser A., et al. Proteomics applied to the clinical follow-up of patients after allogeneic hematopoietic stem cell transplantation. Blood. (2004) 104:340-9. doi: 10.1182/blood-2004-02-0518

39. Sahin U, Dalva K, Gungor F, Ustun C, Beksac M. Donor-recipient killer immunoglobulin like receptor (KIR) genotype matching has a protective effect on chronic graft versus host disease and relapse incidence following HLAidentical sibling hematopoietic stem cell transplantation. Ann Hematol. (2018) 97:1027-39. doi: 10.1007/s00277-018-3274-0

40. Ratanatharathorn V, Deol A, Ayash L, Cronin S, Bhutani D, Lum LG., et al. Low-dose antithymocyte globulin enhanced the efficacy of tacrolimus and mycophenolate for GVHD prophylaxis in recipients of unrelated SCT. Bone Marrow Transplant. (2015) 50:106-12. doi: 10.1038/bmt.2014.203

41. Binkert L, Medinger M, Halter JP, Heim D, Gerull S, Holbro A., et al. Lower dose anti-thymocyte globulin for GvHD prophylaxis results in improved survival after allogeneic stem cell transplantation. Bone Marrow Transplant. (2015) 50:1331-6. doi: 10.1038/bmt.2015.148

42. Ho VT, Soiffer RJ. The history and future of T-cell depletion as graftversus-host disease prophylaxis for allogeneic hematopoietic stem cell transplantation. Blood. (2001) 98:3192-204. doi: 10.1182/blood.V98.12.3192

43. Al-Homsi AS, Roy TS, Cole K, Feng Y, Duffner U. Post-transplant high-dose cyclophosphamide for the prevention of graft-versus-host disease. Biol Blood Marrow Transplant. (2015) 21:604-11. doi: 10.1016/j.bbmt.2014.08.014

44. Rajasagi M, Shukla SA, Fritsch EF, Keskin DB, DeLuca D, Carmona E., et al. Systematic identification of personal tumorspecific neoantigens in chronic lymphocytic leukemia. Blood. (2014) 124:453-62. doi: 10.1182/blood-2014-04-567933

45. Alpdogan O, Van Den Brink MR. Immune tolerance and transplantation \$watermark-text \$watermark-text \$watermark-text. Semin Oncol. (2012) 39:629-42. doi: 10.1053/j.seminoncol.2012.10.001

46. Sampson JK, Sheth NU, Koparde VN, Scalora AF, Serrano MG, Lee V., et al. Whole exome sequencing to estimate alloreactivity potential between donors and recipients in stem cell transplantation. Br J Haematol. (2014) 166:566-70. doi: 10.1111/bjh.12898

47. Jameson-Lee M, Koparde V, Griffith P, Scalora AF, Sampson JK, Khalid H., et al. In silico derivation of HLA-specific alloreactivity potential from whole exome sequencing of stem-cell transplant donors and recipients: understanding the quantitative immunobiology of allogeneic transplantation. Front Immunol. (2014) 5:529. doi: 10.3389/fimmu.2014.00529

48. Lai L, Wang L, Chen H, Zhang J, Yan Q, Ou M., et al. T cell repertoire following kidney transplantation revealed by high-throughput sequencing. Transpl Immunol. (2016) 39:34-45. doi: 10.1016/j.trim.2016.08.006

49. Pröll J, Danzer M, Stabentheiner S, Niklas N, Hackl C, Hofer K., et al. Sequence capture and next generation resequencing of the MHC region highlights potential transplantation determinants in HLA identical haematopoietic stem cell transplantation. DNA Res. (2011) 18:201-210. doi: 10.1093/dnares/dsr008

50. Bykova NA, Malko DB, Efimov GA. In silico analysis of the minor histocompatibility antigen landscape based on the 1000 genomes project. Front Immunol. (2018) 9:1819. doi: 10.3389/fimmu.2018.01819

51. Wang W, Huang H, Halagan M, Vierra-Green C, Heuer M, Brelsford JE., et al. Chromosome Y-encoded antigens associate with acute graft-versus-host 
disease in sex-mismatched stem cell transplant. Blood Adv. (2018) 2:241929. doi: 10.1182/bloodadvances.2018019513

52. Ritari J, Hyvärinen K, Koskela S, Niittyvuopio R, Nihtinen A, Salmenniemi U., et al. Computational Analysis of HLA-presentation of Nonsynonymous recipient mismatches indicates effect on the risk of chronic graft-vs.-host disease after allogeneic HSCT. Front Immunol. (2019) 10:1625. doi: 10.3389/fimmu.2019.01625

53. Martin PJ, Levine DM, Storer BE, Warren EH, Zheng X, Nelson SC., et al. Genome-wide minor histocompatibility matching as related to the risk of graft-versus-host disease. Blood. (2017) 129:791-8. doi: 10.1182/blood-2016-09-737700

54. Lansford JL, Dharmasiri U, Chai S, Hunsucker SA, Bortone DS, Keating JE., et al. Computational modeling and confirmation of leukemiaassociated minor histocompatibility antigens. Blood Adv. (2018) 2:205262. doi: 10.1182/bloodadvances.2018022475

55. Meier J, Roberts C, Avent K, Hazlett A, Berrie J, Payne K., et al. Fractal organization of the human $\mathrm{T}$ cell repertoire in health and after stem cell transplantation. Biol Blood Marrow Transplant. (2013) 19:36677. doi: 10.1016/j.bbmt.2012.12.004

56. Koparde V, Abdul Razzaq B, Suntum T, Sabo R, Scalora A, Serrano M., et al. Dynamical system modeling to simulate donor $\mathrm{T}$ cell response to whole exome sequencing-derived recipient peptides: Understanding randomness in alloreactivity incidence following stem cell transplantation. PLOS ONE. (2017) 12:187771. doi: 10.1371/journal.pone.0187771

57. Toor AA, Sabo RT, Roberts CH, Moore BL, Salman SR, Scalora AF., et al. Dynamical system modeling of immune reconstitution after allogeneic stem cell transplantation identifies patients at risk for adverse outcomes. Biol Blood Marrow Transplant. (2015) 21:1237-45. doi: 10.1016/j.bbmt.2015.03.011

58. Abdul Razzaq B, Scalora A, Koparde VN, Meier J, Mahmood M, Salman S., et al. Dynamical system modeling to simulate donor $t$ cell response to whole exome sequencing-derived recipient peptides demonstrates different alloreactivity potential in HLA-matched and mismatched donor-recipient pairs. Biol Blood Marrow Transplant. (2016) 22:850-61. doi: 10.1016/j.bbmt.2015.11.1103

59. Ott PA, Hu Z, Keskin DB, Shukla SA, Sun J, Bozym DJ., et al. An immunogenic personal neoantigen vaccine for melanoma patients. Nature. (2018) 547:217-21. doi: 10.1038/nature22991

60. Claiborne J, Bandyopathyay D, Roberts C, Hawks K, Aziz M, Simmons G., et al. Managing post allograft relapse of myeloid neoplasms: azacitidine and donor lymphocyte infusions as salvage therapy. Leuk Lymphoma. (2019) 60:2733-43. doi: 10.1080/10428194.2019. 1605066

61. Salman A, Koparde V, Hall CE, Jameson-Lee M, Roberts C, Serrano $\mathrm{M}$., et al. Determining the quantitative principles of $\mathrm{T}$ cell response to antigenic disparity in stem cell transplantation. Front Immunol. (2018) 9:2284. doi: $10.3389 /$ fimmu.2018.02284

62. Łuksza M, Riaz N, Makarov V, Reenbaum BD. A neoantigen fitness model predicts tumor response to checkpoint blockade immunotherapy. Nature. (2017) 176:139-48. doi: 10.1038/nature24462

Conflict of Interest: The authors declare that the research was conducted in the absence of any commercial or financial relationships that could be construed as a potential conflict of interest.

Copyright (๑) 2020 Krieger and Toor. This is an open-access article distributed under the terms of the Creative Commons Attribution License (CC BY). The use, distribution or reproduction in other forums is permitted, provided the original author(s) and the copyright owner(s) are credited and that the original publication in this journal is cited, in accordance with accepted academic practice. No use, distribution or reproduction is permitted which does not comply with these terms. 